\title{
Mechanical properties of unmodified and montmorillonite-modified epoxy compounds. Part I: compression test
}

\author{
Anna Rudawska* (1)
}

\author{
${ }^{*}$ Correspondence: \\ a.rudawska@pollub.pl \\ Faculty of Mechanical \\ Engineering, Lublin \\ University of Technology, \\ Nadbystrzycka 36, \\ 20-618 Lublin, Poland
}

\begin{abstract}
The aim of the article was to determine the compressive strength and compressive strain of an unmodified and a modified epoxy compounds containing a montmorilIonite filler, as well as to determine the effect of temperature and an aging time on the mechanical parameters of the considered epoxy compounds. The subject of the research was both the unmodified and the modified adhesive compounds. The unmodified epoxy compounds were made in four variants, which included the epoxy resins based on a bisphenol $\mathrm{A}$ as well as the curing agents: a triethylenetetramine and a polyamide curing agent. The modified compounds containing the montmorillonite filler, were also made in four variants. The samples were subjected in a thermal chamber at $80^{\circ} \mathrm{C}$ for 1 and 2 months and in a thermal shock chamber in the temperature range from $-40^{\circ} \mathrm{C}$ to $80^{\circ} \mathrm{C}$ for 1 and 2 months. The reference samples were seasoned at room temperature $20-25^{\circ} \mathrm{C}$. The epoxy compounds samples were subjected to the compression strength tests in accordance with ISO 604 standard. The compressive strength is influenced by the environment and temperature, the aging time and the presence of the modifying agent. The epoxy compounds subjected at elevated or variable temperatures have higher compressive strength than the reference epoxy compounds. The operation of the climatic chamber or the thermal shock chamber makes the samples more deformable than the reference samples.
\end{abstract}

Keywords: Compression strength, Temperature, Epoxy compounds, Montmorillonite

\section{Introduction}

The epoxy resins were introduced as industrial products more than 70 years ago. They immediately aroused a great interest due to the valuable properties that distinguish them from other plastics. They found the application in various fields of a technology, especially in electronics and an electrical engineering. Due to their extremely favourable properties and relatively simple processing methods, the epoxy resins are increasingly used in the industry [1]. Their polar nature causes good adhesion of the resins to many different materials, such as a glass, the metals, the polymers, the ceramics and a concrete. During the curing of the resin, slight shrinkage occurs and the castings accurately follow the shape of the mould, making it possible to obtain them without exerting

c) The Author(s), 2021. Open Access This article is licensed under a Creative Commons Attribution 4.0 International License, which permits use, sharing, adaptation, distribution and reproduction in any medium or format, as long as you give appropriate credit to the original author(s) and the source, provide a link to the Creative Commons licence, and indicate if changes were made. The images or other third party material in this article are included in the article's Creative Commons licence, unless indicated otherwise in a credit line to the material. If material is not included in the article's Creative Commons licence and your intended use is not permitted by statutory regulation or exceeds the permitted use, you will need to obtain permission directly from the copyright holder. To view a copy of this licence, visit http:// creativecommons.org/licenses/by/4.0/. 
pressure. The internal stresses are very slight. The cured resins have high mechanical strength and resistance to the influence of weather conditions and chemicals. By adding the fillers to the resin, it is possible to obtain the epoxy materials with different properties [2-5]. In order to modify the properties of the epoxy compounds, various additives (fillers) are added. The one of important filler is montmorillonite. It is assumed that composites with a filler content in the form of montmorillonite from 2 to $10 \%$ by weight are characterized, among others, by better mechanical properties, as well as an increase in thermal stability. The characteristics of this filler have been presented in numerous works [5-8].

During operation, the epoxy compounds in a variety of applications, including as adhesives in the adhesive joints or as coatings, are exposed to various external factors. Unlike other materials, the polymers show a clear dependence of the mechanical properties on the external factors, mainly temperature, which should be taken into account when using these materials in various operating conditions. Many researchers emphasize the importance of acquaintance changes in both the adhesives and the adhesive joints under the influence of various conditions (e.g. temperature, thermal shock, time, humidity, etc.) [9-14]. Zhang et al. [15] underlined that one aspect still lack of understanding with respect to other adhesive applications is the crash resistance of the adhesive bonds after their short-term or long-term hygrothermal exposure. Han et al. [16] presented the issue of investigating the residual static strength of adhesively bonded joints after a longterm exposure to a combined mechanical-hygro-thermal environment. Okba et al. [17] investigated the effect of temperature and time on the mechanical properties of polymer adhesives and they noticed that the decrease of strength depends on the type of the polymer, a temperature, the time and the applied stress. Da Silva and Adams [18] presented some issue of the adhesive joints designing suitable for use from low to high-temperatures, by the combination of two adhesives, one for strength at high-temperatures and one for strength at low-temperatures. Viana et al. [9] undelined that despite offering very attractive advantages over traditional joining methods, one of the setbacks of the adhesive bonding is its long-term strength in aggressive environments, such as environments with high moisture and extreme temperatures. They presented a review on temperature and the moisture degradation of the adhesive joints. Hu et al. [19] presented the static mechanical performance of the adhesively bonded joints after different temperature an exposure was investigated through joint quasi-static shear-strength test. The test results demonstrated that long-term temperature exposure caused the degradation in the joint strength and the failure displacement. Beber et al. [20] underlined that the bonded joints are exposed to a cyclic loading under a broad range of temperatures during their service life and the fatigue tests showed there was a reduction in fatigue lifetime with increasing temperature.

In this work the influence of various conditions (temperature, thermal shock and time of aging) on the mechanical properties (compressive strength and compressive strain) of the unmodified and the modified epoxy compounds containing a montmorillonite filler, was determined. The results of the compressive strength tests are used, inter alia, to characterize the polymer materials when a given material is to be used as a material transferring compressive stresses. The compressive strength answers the question of what the load should be applied in order for the structure of the polymer material to 
Table 1 Selected properties of epoxy resins

\begin{tabular}{lll}
\hline Properties & Epoxy resin type \\
\cline { 2 - 3 } & Epidian $\mathbf{5}$ & Epidian $\mathbf{5 7}$ \\
\hline Epoxy number $(\mathrm{mol} / 100 \mathrm{~g})$ & $0.49-0.52$ & 0.40 \\
Density $\left(\mathrm{g} / \mathrm{cm}^{3}\right)$ at $20^{\circ} \mathrm{C}$ & 1.17 & $1.14-1.17$ \\
Viscosity $(\mathrm{mPas})$ at $25^{\circ} \mathrm{C}$ & max. 30,000 & $13,000-19,000$ \\
Base & Unmodified base resin & Epoxy compound \\
& & modified with polyester \\
& & resin \\
\hline
\end{tabular}

Table 2 Selected properties of curing agents

\begin{tabular}{lcl}
\hline Properties & \multicolumn{2}{c}{ Curing agent type } \\
\cline { 2 - 3 } & Polyaminoamide & Triethylenotetramine \\
\hline Amine number $(\mathrm{mg} \mathrm{KOH} / \mathrm{g})$ & $290-360$ & 1100 \\
Density $\left(\mathrm{g} / \mathrm{cm}^{3}\right)$ at $20^{\circ} \mathrm{C}$ & $1.10-1.20$ & $0.978-0.983$ \\
Viscosity $(\mathrm{mPas})$ at $25^{\circ} \mathrm{C}$ & $10,000-25,000$ & $20-30$ \\
\hline
\end{tabular}

be damaged. The higher the value of the compressive strength, the greater the loads can be applied to the polymer material (as a structural element (in a specific structure). The issues of the compressive strength of the epoxy materials in various forms are presented, inter alia, in works [21-23].

\section{Methodology}

\section{Characteristics of epoxy compounds}

Two types of epoxy compounds were used in the research: the unmodified and the modified. Eight types of the epoxy compounds were prepared for the tests, made of two types of the epoxy resins based on the bisphenol A resins (Epidian 5 and Epidian 57 trade name, CIECH Resins, Nowa Sarzyna, Poland) and two types of the curing agents: a polyaminoamide curing agent (PAC trade name, CIECH Resins, Nowa Sarzyna, Poland) and a triethylenetetramine curing agent (Z-1 trade name, CIECH Resins, Nowa Sarzyna, Poland) and montmorillonite filler (NanoBent ZR2 trade name, ZGM "Zębiec" S.A., Zębiec, Poland). The selected properties of the epoxy compounds components are listed in Tables 1 and 2 [3, 24-26].

The montmorillonite in the form of ZR2 Nanobent is a mineral of volcanic origin, the density of which is around $1.9-2.7 \mathrm{~g} / \mathrm{cm}^{3}$. The montmorillonite is a layered silicate with a lamellar structure. The thickness of the plate is $0.96 \mathrm{~nm}$, and its other dimensions are in the range of 200-1000 nm. ZR2 Nanobent is made of three layers: two external tetrahedrons (in the shape of a silicon-oxygen tetrahedron), between which there is one octahedral layer (octahedron formed by the surrounding of iron, magnesium or aluminium ions with hydroxyl groups and oxygen atoms). All layers are held together by shared oxygen atoms. The forces connecting the layers are the Van der Waals forces. The distance between successive montmorillonite plates is approx. $0.3 \mathrm{~nm}$. Several (5-9) parallel plates constitute the primary montmorillonite particle with a thickness of approx. $7-12 \mathrm{~nm} 6-8$. The characteristics of this type of the filler have been presented in $[5,27]$. 
Table 3 Types of unmodified epoxy compounds used in the research

\begin{tabular}{llll}
\hline $\begin{array}{l}\text { Compositions of epoxy } \\
\text { compounds: epoxy resin/curing } \\
\text { agent }\end{array}$ & $\begin{array}{l}\text { Components proportions } \\
\text { of epoxy compounds }\end{array}$ & Designation & $\begin{array}{l}\text { Amount of sample } \\
\text { (cylindrical sample) }\end{array}$ \\
\hline Epidian 5/PAC & $100: 80$ & E5/PAC/100:80 & 30 \\
Epidian 5/Z-1 & $100: 10$ & E5/Z-1/100:10 & 30 \\
Epidian 57/PAC & $100: 80$ & E57/PAC/100:80 & 30 \\
Epidian 57/Z-1 & $100: 10$ & E57/Z-1/100:10 & 30 \\
Sum & & & 120 \\
\hline
\end{tabular}

Table 4 Types of modified epoxy compounds used in the research

\begin{tabular}{llll}
\hline $\begin{array}{l}\text { Compositions of epoxy } \\
\text { compounds: epoxy resin/curing } \\
\text { agent }\end{array}$ & $\begin{array}{l}\text { Components } \\
\text { proportions of epoxy } \\
\text { compounds }\end{array}$ & Designation & $\begin{array}{l}\text { Amount of sample } \\
\text { (cylindrical sample) }\end{array}$ \\
\hline Epidian 5/PAC/ZR2 & $100: 80: 2$ & E5/PAC/ZR2/100:80:2 & 30 \\
Epidian 5/Z-1/ZR2 & $100: 10: 2$ & E5/Z-1/ZR2/100:10:2 & 30 \\
Epidian 57/PAC/ZR2 & $100: 80: 2$ & E57/PAC/ZR2/100:80:2 & 30 \\
Epidian 57/Z-1/ZR2 & $100: 10: 2$ & E57/Z-1/ZR2/100:10:2 & 30 \\
Sum & & & 120 \\
\hline
\end{tabular}

The unmodified compounds, consisting of the resin and the curing agent, as well as the modified compounds additionally containing a filler, were prepared from the abovementioned components.

The amount of the curing agent per $100 \mathrm{~g}$ the epoxy resin was applied within the recommended stoichiometric ratio. Adding the curing agent to the epoxy resin starts the curing process, which transforms the adhesive from a liquid consistency into a solid state. For the used the epoxy resins and the polyaminoamide curing agent with an amine number between 290 and $360 \mathrm{mg} \mathrm{KOH} / \mathrm{g}$, a ratio of 100:80 was taken from the recommended range. A ratio of 100 parts by weight of aa epoxy resin and 10 parts by weight of a curing agent was used for epoxy compounds containing the epoxy resins and the triethyleneteramine curing agent (1100 $\mathrm{mg} \mathrm{KOH} / \mathrm{g}$ amine number). The amount of used filler in the form of montmorillonite was adopted due to the results of previous studies $[5,27]$.

The types of the epoxy compounds (unmodified and modified with the montmorillonite), the proportions of the epoxy compounds components and the number of the epoxy compounds samples of a given type are presented in Tables 3 and 4 .

\section{Shape and dimensions of the epoxy compounds samples}

In order to carry out the compressive strength test, the cylindrical samples were made.

The samples were made using the cylindrical polyethylene moulds. Form in the cylindrical form, it made it possible to give the samples a specific diameter $\mathrm{d}$. The final sample length, the same for all samples, was given in the milling process. The shape and the dimensions of the cylindrical sample are shown in Fig. 1a and an example of a sample made of the Epidian 57 epoxy resin and the polyaminoamide curing agent is shown in Fig. 1b. 
(a)

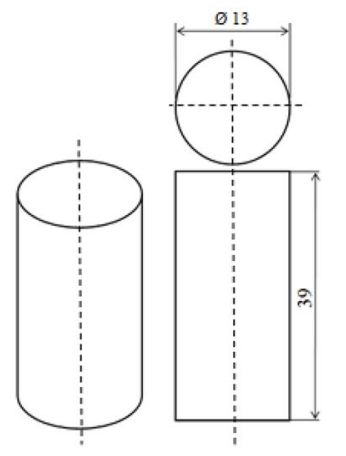

(b)

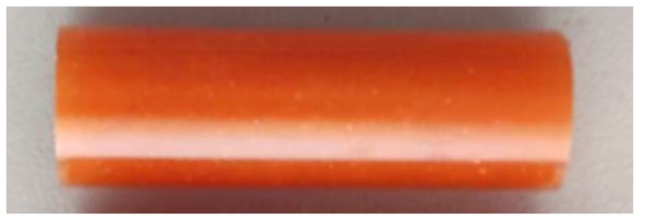

Fig. 1 Cylindrical sample epoxy compound for compressive strength test: a shape and dimension in $\mathrm{mm}$. $\mathbf{b}$ Example of epoxy compound sample

The cylindrical specimens were made of all the epoxy compounds presented in Tables 3 and 4 (30 samples per each type of epoxy compounds). Then, the samples were checked for the presence of the air bubbles on the milled frontal surfaces.

\section{Technology of preparing epoxy compounds}

The preparation of the adhesive compounds involved a series of steps that led to the formation of the epoxy compounds from the individual components (resin, curing agnet and filler), which was the epoxy compounds ready for further research. The preparation of the epoxy compounds consisted in the preparation of appropriate ingredients, their batching, dosing, mixing and aging. The preparation of the epoxy compounds took place in the folowing conditions: at room temperature $22-25^{\circ} \mathrm{C}$ and air humidity of $24 \pm 2 \%$.

The right amount of the ingredients (the epoxy resins, curing agents and filler) for each epoxy compounds were batched with an electronic scale (TP-2 type, FAWAG S.A, Lublin, Poland) using a polyethylene cup. In the case of the modified epoxy compounds, the filler was added to the epoxy resin and both ingredients are thoroughly mixed, and after then then the appropriate amount of curing was added, keeping the required ratio of the epoxy resin to the curing agent and again mixed. The components of the epoxy compounds were mechanically mixed using an anchor stirrer at a speed of 460 RPM for $90 \mathrm{~s}$ using a stand for mixing adhesives. After mixing the epoxy compounds were kept under vacuum for $90 \mathrm{~s}$.

The obtained each epoxy mass was placed in the prepared the cylindrical moulds in the form polyethylene with a capacity of $5 \mathrm{ml}$. The inner diameter of the mould provided the assumed sample size. The moulds were filled with adhesive mass up to the $5 \mathrm{ml}$ mark and then held down with the plunger in order to move all air bubbles in the adhesive towards the conical connector. The ratio of the length of the cylindrical sample to its diameter for the strength tests should be $3: 1$. In order to obtain this ratio and obtain the perpendicular to the axis of the front surface, the samples taken out of the moulds were subjected to the milling process using FNB 26 milling machine and six-edge cutter. The milling speed was $128 \mathrm{~m} / \mathrm{min}$, and feed per tooth for samples E5/ PAC and Epidian 5/Z-1 was $0.008 \mathrm{~mm} /$ tooth, while for samples E57/PAC and E57/Z-1) was $0.011 \mathrm{~mm} /$ tooth. In order to mill the samples, they were placed in a special form that allowed for 
the simultaneous machining of 5 samples. It was very important to properly press both parts of the mould, as this prevented the samples from being torn out by the rotating cutter.

\section{Aging conditions}

The prepared epoxy compounds specimens (cured, of the same dimensions) were subjected to operation in various environments and for different times. Description of these environments is presented in Table 5.

Six specimens of each epoxy compounds were subjected to each condition. A total of 120 samples of the unmodified epoxy compounds and 120 samples of the modified epoxy compounds were tested, which gave a total of 240 specimens subjected to conditions mentioned in Table 5.

The reference samples were seasoned under laboratory conditions at a temperature of $23-25^{\circ} \mathrm{C}$ and an air humidity of $24 \%$. Two variations of the aging times 1 and 2 months were used. The samples were seasoned at an elevated temperature in Espec SH-661 (ESPEC EUROPE GmbH, distributed by Klimatest, Poland) in which the temperature was set to $80{ }^{\circ} \mathrm{C}$ and the relative humidity to $95 \%$. The samples were put into the climate chamber on the special aluminium trays, on which the samples were arranged in such a way that they did not touch each other. Two variations of the aging times 1 and 2 months were used. The third group of the samples was subjected to a thermal shock treatment with the use of a thermal shock chamber Espec TSE-11 (distributed by Klimatest, Poland). The aging time was 2 months.

\section{Strength test}

The specimens of the epoxy compounds, after aging in the appropriate conditions (Table 5), were subjected to the compression strength tests. All tested specimens were tested on Zwick/Roell Z150 testing machine (ZwickRoell GmbH\&Co. KG, Ulm, Germany) in the laboratory conditions at room temperature and an air humidity of $24 \%$. The static compression test was performed based on the ISO 604 standard and consisted in squeezing a cylinder-shaped sample placed in a special holder and determining the mechanical properties of the epoxy compounds from which the sample was made (Fig. 2).

Table 5 Aging conditions of unmodified and modified epoxy compounds

\begin{tabular}{|c|c|c|c|c|c|}
\hline \multirow[t]{4}{*}{ Quantity } & \multicolumn{5}{|c|}{ Aging conditions } \\
\hline & \multicolumn{5}{|l|}{ Designation } \\
\hline & \multicolumn{2}{|l|}{$\mathbf{R}$} & \multicolumn{2}{|l|}{$\mathrm{CC}$} & TSC \\
\hline & \multicolumn{2}{|l|}{ Reference } & \multicolumn{2}{|c|}{ Climatic chamber } & $\overline{\text { Thermal shock chamber }}$ \\
\hline Temperature & $23-25^{\circ} \mathrm{C}$ & & $80^{\circ} \mathrm{C}$ & & $-40^{\circ} \mathrm{C} /+80^{\circ} \mathrm{C}$ \\
\hline Humidity & $24 \pm 2 \% \mathrm{RH}$ & & $95 \% \mathrm{RH}$ & & - \\
\hline Number of cycles & - & & - & & 2000 \\
\hline Time of cycle & - & & - & & $15 \mathrm{~min}$ \\
\hline Time of aging & 1 month & 2 months & 1 month & 2 months & 2 months \\
\hline
\end{tabular}




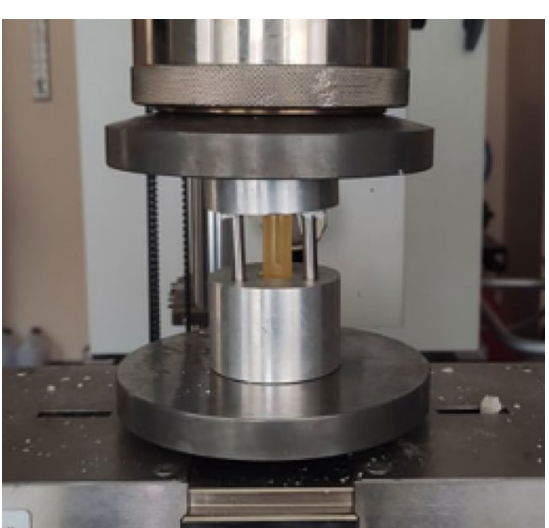

Fig. 2 Cylindrical sample placed in special holder on testing machine

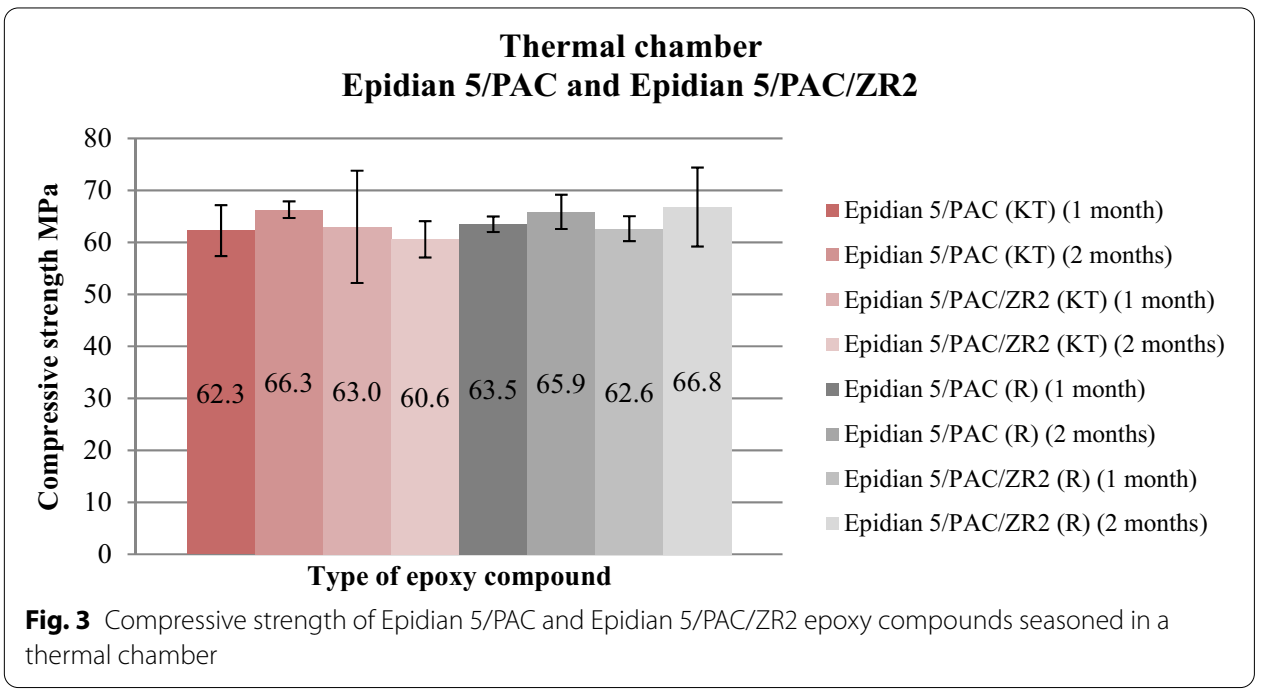

The holder with the specimen was placed in the testing machine and compressed at a speed of $10 \mathrm{~mm} / \mathrm{min}$. The squeezing planes (handles of the testing machine) occupied a position parallel to the plane of the sample bases. The traverse speed when determining the compression modulus was $1 \mathrm{~mm} / \mathrm{min}$. The initial force loading the sample was set to $10 \mathrm{~N}$. The tested strength parameters are: the compression strength $\sigma_{\mathrm{M}}$ and the compressive strain $\varepsilon_{\mathrm{M}}$. The compressive strength is calculated by dividing the maximum load by the original cross-sectional area of the sample subjected to the compression test.

\section{Results: compression strength} Epidian 5/PAC

A comparison of the results of the compression strength for Epidian 5/PAC and Epidian 5/PAC/ZR2 epoxy compounds operated in temperature environments at various times are shown in Figs. 3 and 4.

The comparison of the results shown in Fig. 3 shows that it is not possible to unequivocally state what the effect on the compressive strength is exerted by the extension 


\section{Thermal shock chamber Epidian 5/PAC and Epidian 5/PAC/ZR2}

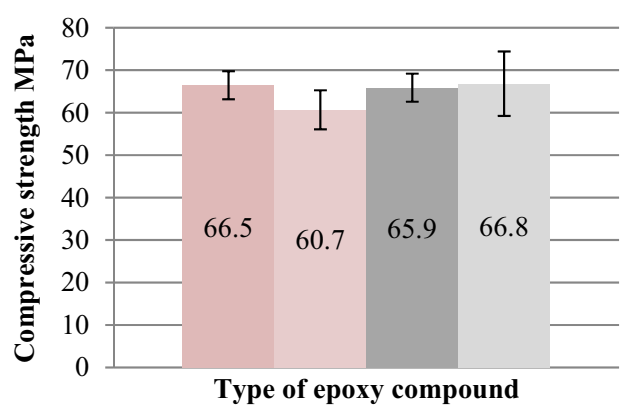

Epidian 5/PAC (KSZ)

Epidian 5/PAC/ZR2 (KSZ)

- Epidian 5/PAC (R)

Epidian 5/PAC/ZR2 (R)

Type of epoxy compound

Fig. 4 Compressive strength of Epidian 5/PAC and Epidian 5/PAC/ZR2 epoxy compounds seasoned in a thermal shock chamber

of the aging life of the epoxy compounds in the climatic chamber. For Epidian 5/PAC epoxy compounds, longer aging time of the samples increases their strength by $6.4 \%$, while for Epidian 5/PAC/ZR2 epoxy compounds it was decreased by $3.8 \%$. Same as in the case of the reference samples $(R)$, the samples subjected in the thermal chamber have a similar compressive strength, therefore it can be concluded that the modification of the epoxy compounds with the montmorillonite slightly affects the results. It can also be seen that the strength of the epoxy compounds put in the thermal chamber and the reference compositions is at a very similar level. Thus, for the tested temperature variant, the result of the strength is insignificant.

Comparing the results obtained for the reference samples (R), it was noticed that the longer subjecting time of the samples ( 2 months) had a positive effect on the value of compressive strength, causing its increase. A slightly higher increase, amounting to $6.7 \%$, can be observed in the case of the modified epoxy compounds. In turn, for the second epoxy compounds, the increase in strength oscillates around $3.8 \%$. All the results presented in the diagram are of a similar value and are in the range of 60-70 MPa, therefore it can be concluded that the filler content has a slight influence on the strength of epoxy compounds.

After analysing the data presented in Fig. 4 it is stated that the addition of a modifying agent to the epoxy compound deteriorates its compressive strength, measured after operation in a thermal shock chamber for 2 months. A decrease in strength can be observed, amounting to $8.9 \%$. The strength of the compounds aged in both environments is at a similar level. The maximum difference is $10 \%$ (for the modified epoxy compound).

A comparison of the results of the compressive strain for Epidian 5/PAC and Epidian 5/PAC/ZR2 epoxy compounds subjected in temperature environments at various times are shown in Figs. 5 and 6.

Analysing the graphical summary of the results (Fig. 5) it can be observed that the extension of the period of placing the epoxy compound in the climatic chamber causes an increase in the compressive strain for the unmodified epoxy compound and a decrease in this value for the modified epoxy compound. The decrease in the value of the compressive strain is much greater, amounting to $59.4 \%$. The greatest compressive 

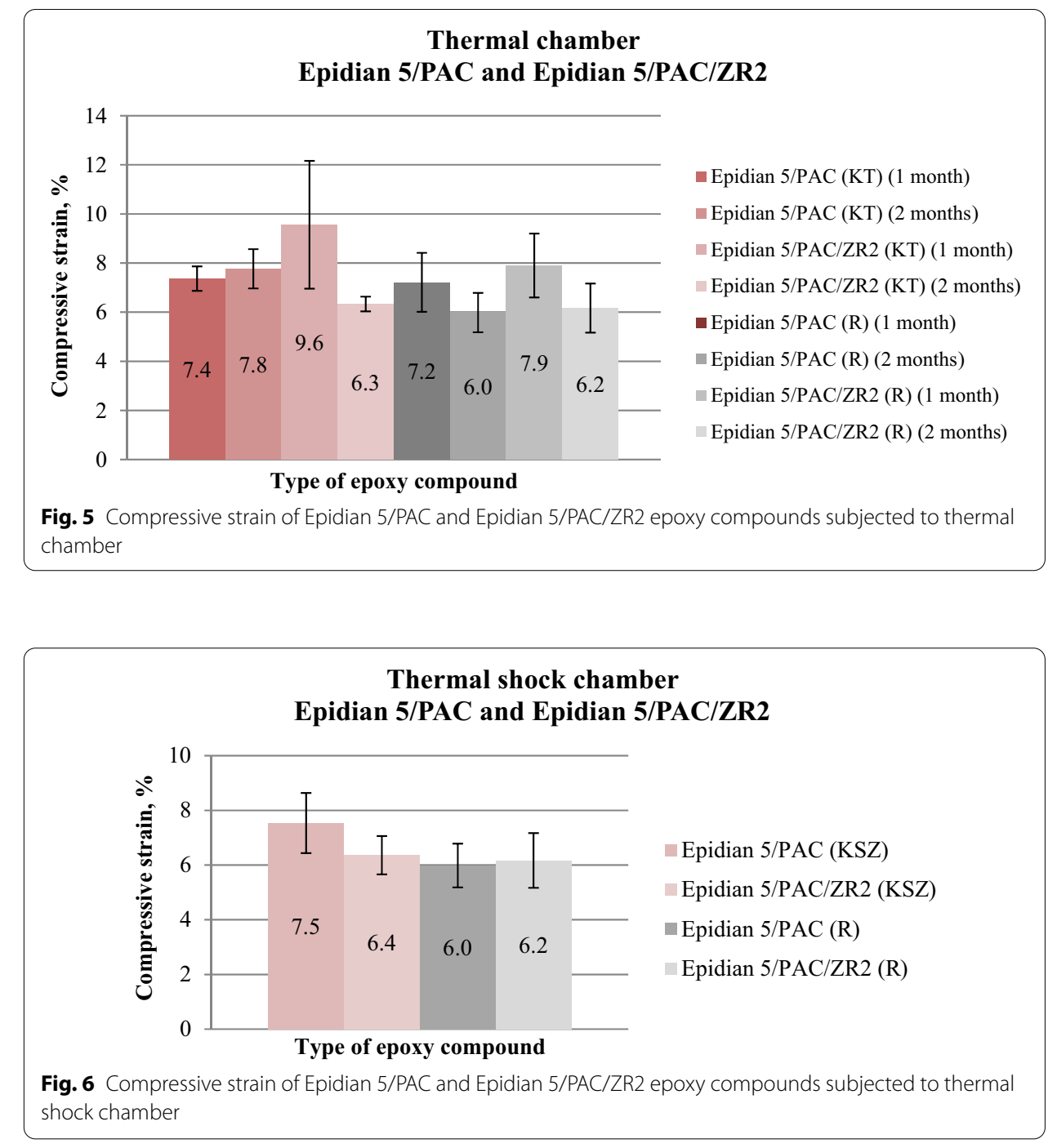

strain of the samples occurs in the case of the compression of the modified epoxy compound aged for a month, and the smallest in the case of the same epoxy compound subjected to aging for 2 months. It can be noticed that samples aged at a higher temperature are shorter during compression than the reference samples (R). With reference to the reference samples (R), when analysing the graphical summary of the results (Fig. 5), it is possible to observe a decrease in the value of the compressive strain for the epoxy compound aged for 2 months, compared to the values observed for the samples after a month of aging. These values for both epoxy compounds are very similar. The difference for the unmodified epoxy compound is $16.7 \%$, and for the epoxy compound containing the filler is $21.5 \%$. Epidian 5/PAC/ZR2 (R) reference epoxy compound, seasoned for 1 month, showed the greatest shortening. In the case of the monthly aging period, a difference in the decreasing value of the samples of both epoxy compounds can be noticed, which may indicate the dependence of this parameter on the applied modifier.

Based on the comparison of the results presented in Fig. 6, it was found that the filler content in the form of the montmorillonite reduces the value of the compressive strain 

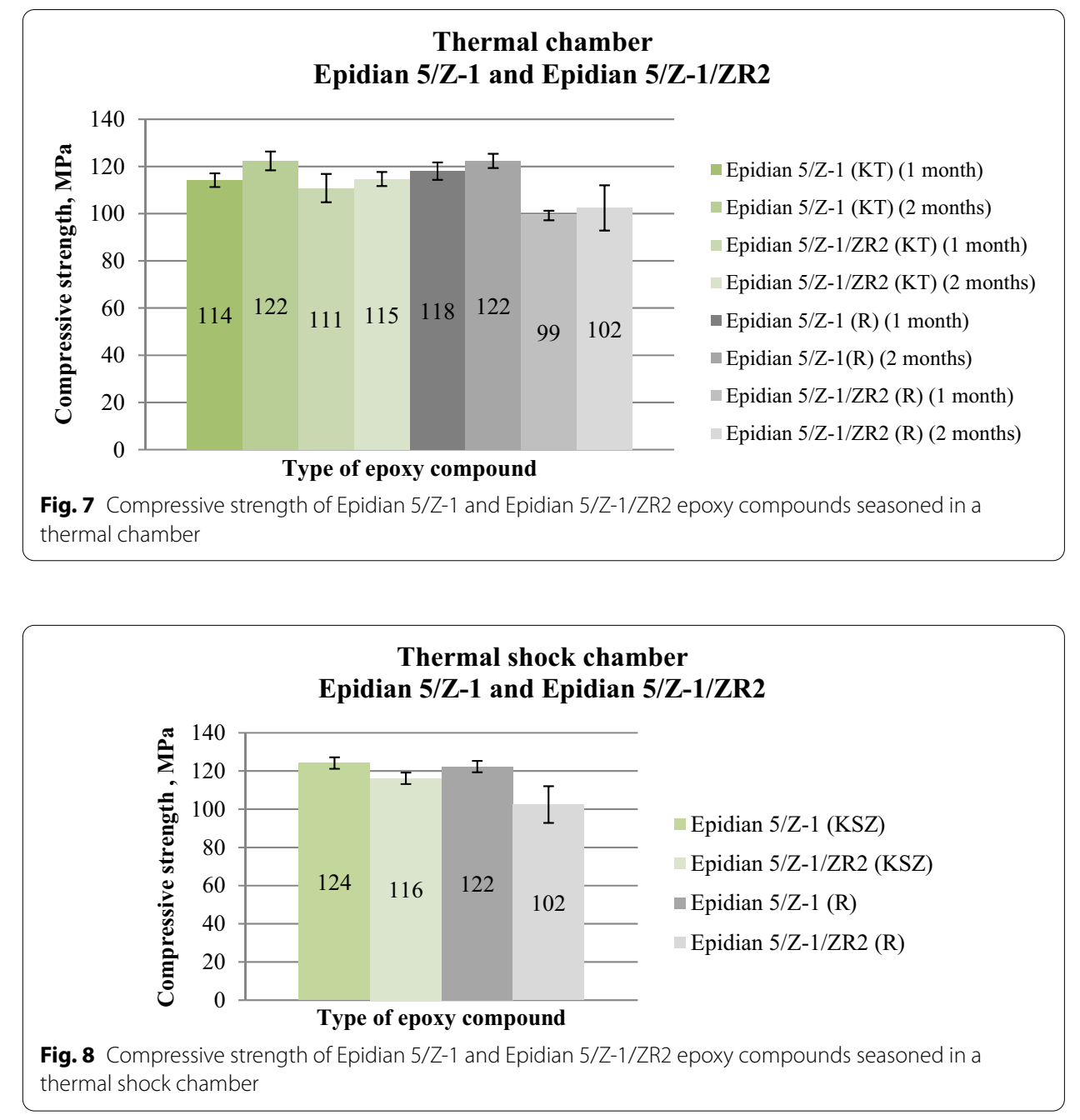

of the compounds subjected to thermal shocks. The decline is $25.3 \%$. It can also be seen that the compressive strain of the seasoned epoxy compounds in the shock chamber is higher than the reference epoxy compounds $(\mathrm{R})$, therefore the variable aging temperature increases the deformation of the tested epoxy compounds.

\section{Epidian 5/Z-1}

Figures 7 and 8 present the comparisons of the results of the compression test of the Epidian 5/Z-1 and Epidian 5/Z-1/ZR2 epoxy compounds subjected to different environments.

As regards the reference samples, the results of the compression test presented in Fig. 7 show that the aging of the epoxy compounds samples for a longer time ( 2 months) contributes to the improvement of the compressive strength of both epoxy compounds. In both cases, the increase is small and amounts to approx. 3\%. Epidian 5/Z-1 (R) reference epoxy compound, seasoned for 2 months, is characterized by the highest strength, while the modified epoxy compound has the lowest with the aging period of 1 month. A significant difference in the results between the modified and unmodified epoxy 
compounds can be seen, which shows that the modifying agent also has an influence on the compressive strength.

Based on the analysis of the obtained results (Fig. 7), it is stated that extending the period of placing the epoxy compounds in the thermal chamber from 1 to 2 months increases the strength of both epoxy compounds. A slightly greater increase of $7 \%$ can be observed for the Epidian 5/Z-1 (KT) formulation. In turn, the strength of the modified epoxy compound increased by $3.6 \%$. The results of the strength of all epoxy compounds are in the range of 110-115 MPa, therefore it can be concluded that the presence of the filler slightly affects the strength of the tested epoxy compounds. For the modified epoxy compound, seasoned in a climate chamber, an increase in the compressive strength is observed compared to the compound seasoned under the reference conditions. On the other hand, for the unmodified epoxy compound, no difference can be observed (the epoxy compound is seasoned for 2 months) or a slight decrease in the strength (the epoxy compound is seasoned for a month).

When analysing the results presented in Fig. 8, slight reductions in the compressive strength of the modified epoxy compound are noticeable in relation to the unmodified epoxy compound operated for the same period of time in a thermal shock chamber. The value of the decline is $6.5 \%$. Aging the samples at changing temperatures it increases their compressive strength.

Figures 9 and 10 present comparisons of the results of the compressive strain of Epidian 5/Z-1 and Epidian 5/Z-1/ZR2 epoxy compounds subjected to the different environments for the different periods of time.

The comparison of the results presented in Fig. 9 makes it possible to conclude that the extension of the aging time of the epoxy compound in the climate chamber reduces their compressive strain. A slightly greater decrease is characteristic of the modified epoxy compound, reaching the value of $13.5 \%$. It is also the difference between the highest and the lowest value of the examined parameter. It is possible to observe a slight influence of the presence of the modifier on the result of shortening in both periods of the aging, in the case of a monthly aging period it causes an increase, and in the case of a two-month

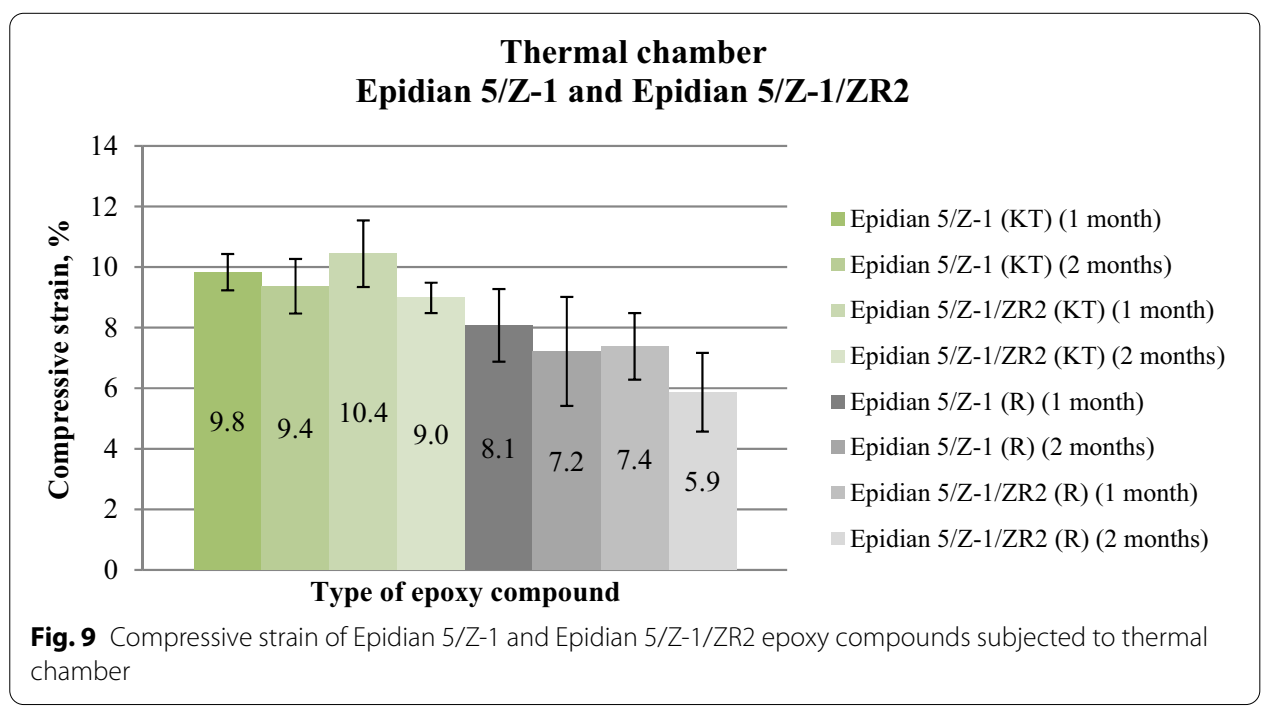




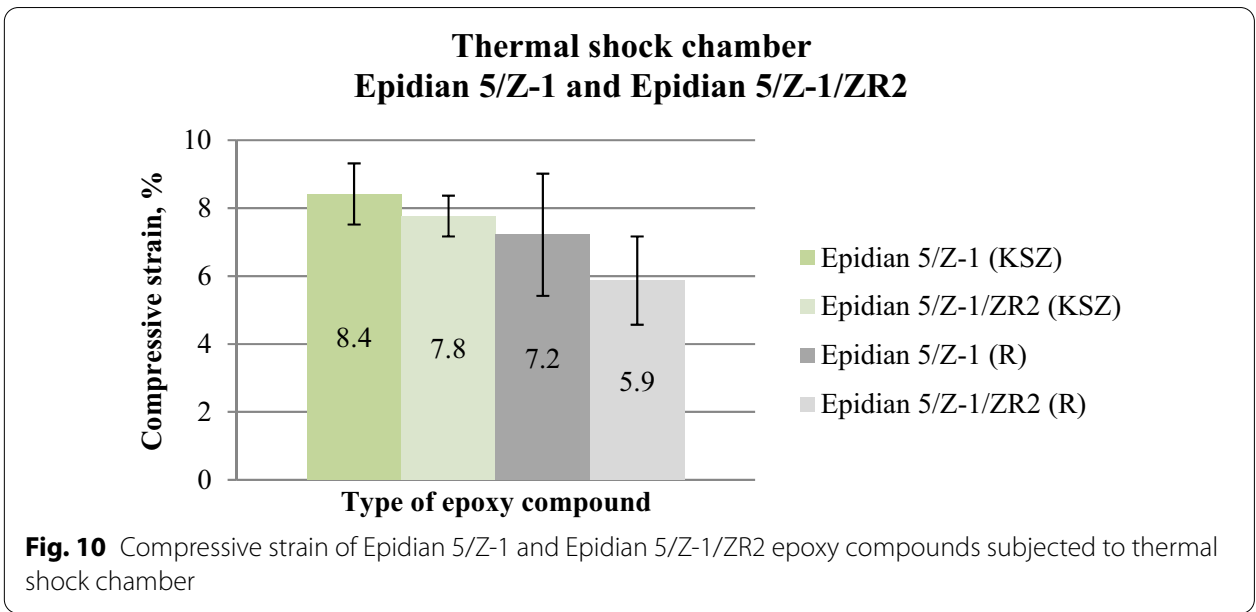

period, a decrease in the results. It can be seen that the described epoxy compounds shorten much more when compressed than the reference epoxy compound (R).

The summary of data presented in Fig. 9 shows that in the case of the tested references epoxy compounds $(\mathrm{R})$, the deformation of the samples decreases with the extension of their aging period. A visibly greater decrease is observed for the reference epoxy compound with the addition of the modifier, it amounts to $20.3 \%$. The greatest compressive strain result was recorded for the Epidian 5/Z-1 (R) epoxy compound which was seasoned shorter, and the lowest for the Epidian 5/Z-1/ZR2 (R) epoxy compound which was seasoned for a longer time. The different results of the tested value were obtained for particular periods of aging, so it can be concluded that it depends on the presence of the filler modifying the compound.

Analysing the data presented in Fig. 10, a slight decrease of the compressive strain was observed for the modified epoxy compound aged in a thermal shock chamber, compared to the compound without the addition of the filler. This decrease is $7.1 \%$. There is a significant increase in the deformation of samples seasoned at a higher temperature compared to the reference samples. The difference is greater for Epidian 5/Z-1/ZR2 and amounts to $32.2 \%$.

\section{Epidian 57/PAC}

Figures 11, 12, 13 and 14 compare the results of the compression test of Epidian 57/PAC and Epidian 57/PAC/ZR2 epoxy compounds in different environments for different periods of time.

As results from the comparison of the results obtained for the reference samples (R) showed in Fig. 11, the extension of the aging time of the samples of the epoxy compounds results in a decrease in its strength in the case of unmodified and modified epoxy compounds. A visibly greater decrease in the strength value can be seen for Epidian $57 / \mathrm{PAC}(\mathrm{R})$, reaching a value of $12.6 \%$. It can also be read from the drawing that the unmodified epoxy compound, seasoned for a shorter time, has the highest strength, and the lowest strength is that of a modified epoxy compound, seasoned for 2 months. The results for the two epoxy compounds are different from each other, which mean that the filler content affects the strength. 

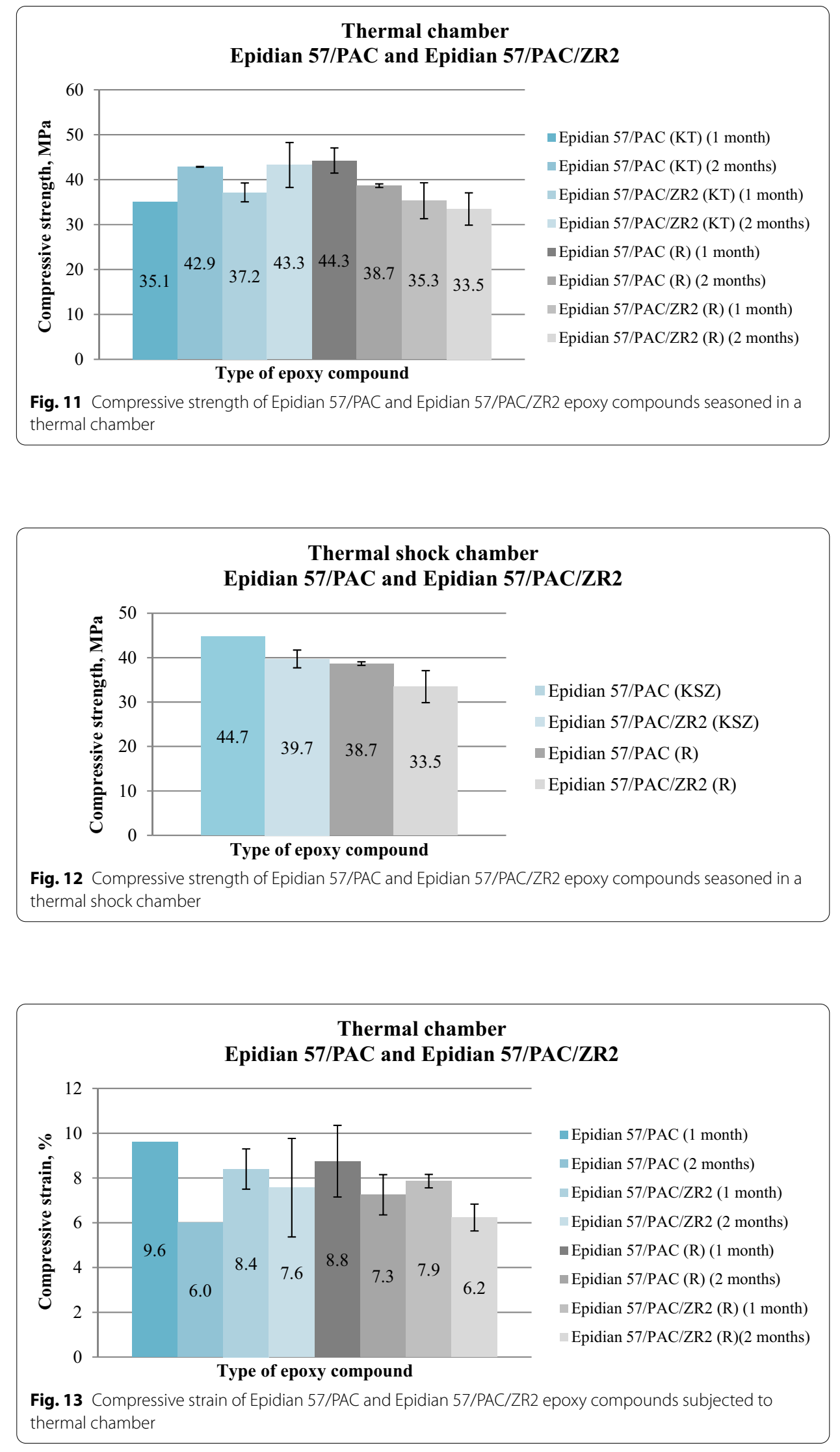


\section{Thermal shock chamber Epidian 57/PAC and Epidian 57/PAC/ZR2}

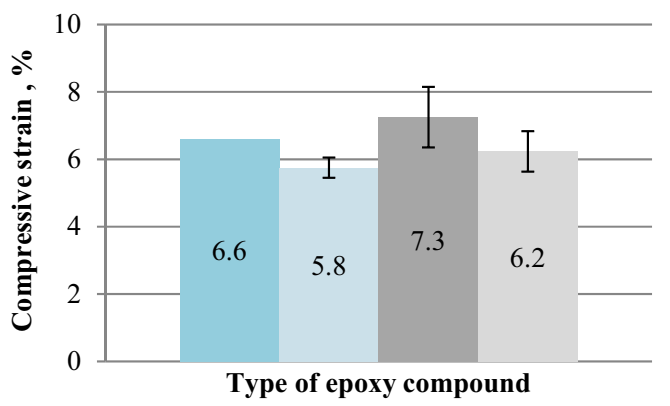

Epidian 57/PAC (KSZ)

Epidian 57/PAC/ZR2 (KSZ)

Epidian 57/PAC (R)

Epidian 57/PAC/ZR2 (R)

Type of epoxy compound

Fig. 14 Compressive strain of Epidian 57/PAC and Epidian 57/PAC/ZR2 epoxy compounds subjected to thermal shock chamber

Analysing the comparison of the results presented in Fig. 11, it was found that subjecting the epoxy compound for a longer time in the thermal chamber has a positive effect on the strength value. A slightly greater increase, equal to $22.2 \%$, can be observed in the case of Epidian 57/PAC (KT) epoxy compound. Due to the addition of the filler, the strength of the modified epoxy compound after a aging life of one month is higher than that of the epoxy compound without montmorillonite content. It can therefore be concluded that the addition of the filler improves the strength of the epoxy compound over a given lifetime. The modified epoxy compound has the highest compressive strength after 2 months of aging, while the unmodified epoxy compound has the lowest seasoned for a shorter period. In almost all cases, an increase in the operating temperature increases the compressive strength. The exception is the epoxy compound without the filler, seasoned for 1 month; it is characterized by higher strength after aging in the laboratory conditions.

When analysing the graphical summary of the results (Fig. 12), a decrease in the strength of Epidian 57/PAC/ZR2 (KSZ) epoxy compound subjected to thermal shocks was noticed compared to Epidian 57/PAC (KSZ) epoxy compound. It can therefore be concluded that the presence of the modifying agent reduces the strength of the epoxy compound. The drop in value is at the level of $11.2 \%$. As shown in the figure above, the epoxy compound which is seasoned at changing temperatures is more strength.

After analysing the data shown in Fig. 13, it is found that subecting the epoxy compound to the thermal chamber for a longer period of time results in a decrease in relative contraction. The unmodified epoxy compound shows a much greater decrease, it amounts to $37.5 \%$. The smallest and the largest value of the compressive strain are included in the results of Epidian 57/PAC (KT) epoxy compound. The largest is for the epoxy compound subjected to a shorter period of time, and the smallest for the epoxy compound which is seasoned for 2 months. The influence of the modifier's presence on the shaping of the shortening results can be noticed. In the first month of aging, it causes a decrease, and in the second, an increase in the value of the tested parameter. In most cases, the relative reduction is greater for the epoxy compounds with high operating temperature, with the exception of the epoxy compound without the addition of the filler, aged for 2 months. 
After analysing the results shown in Fig. 13, refers to reference samples (R), the tendency of the epoxy compound to decrease the compressive strain due to the extension of the aging time of the samples from 1 to 2 months can be noticed. In the case of both epoxy compounds, the decrease fluctuates around $20 \%$. The unmodified epoxy compound with a monthly aging period has the greatest reduction, and the modified epoxy compound, seasoned within 2 months, has the lowest reduction. It can be seen that for a given period of the aging, the values of both epoxy compounds differ from each other, so the impact of the filler content on the result of the compressive strain is noticeable here.

On the basis of the graphical summary of the results (Fig. 14), it can be noticed that the presence of the filler in the epoxy compound subjected to the thermal shocks reduces the value of its shortening. This change amounts to $12.1 \%$. The compressive strain for the epoxy compound seasoned in both environments is at a similar level, but the reference samples are shortened slightly more.

\section{Epidian 57/Z-1}

Figures 15, 16, 17 and 18 present the comparisons of the compressive strength values for Epidian 57/Z-1 and Epidian 57/Z-1/ZR2 epoxy compounds, which were subjected to the various conditions and periods.

Based on the comparison of the results shown in Fig. 15, a slight decrease in compressive strength can be observed for the compounds aged for a longer time compared to the compounds aged for a shorter time. The decrease for each of the two compounds is similar at a maximum of $2.2 \%$. The results for the modified and unmodified compounds in given periods differ from each other, hence it can be concluded that the modification of the compound with montmorillonite affects the strength. The compound of Epidian 57/Z-1 (R) modified for a longer time has the highest value, while the compound of Epidian 57/Z-1/ZR2 (R) modified for a shorter time has the lowest value.

The summary of the data presented in Fig. 15 shows that the extension of the seasoning life of the samples in the thermal chamber increases the compressive strength of the tested epoxy compounds. The increase for each of the two epoxy compounds

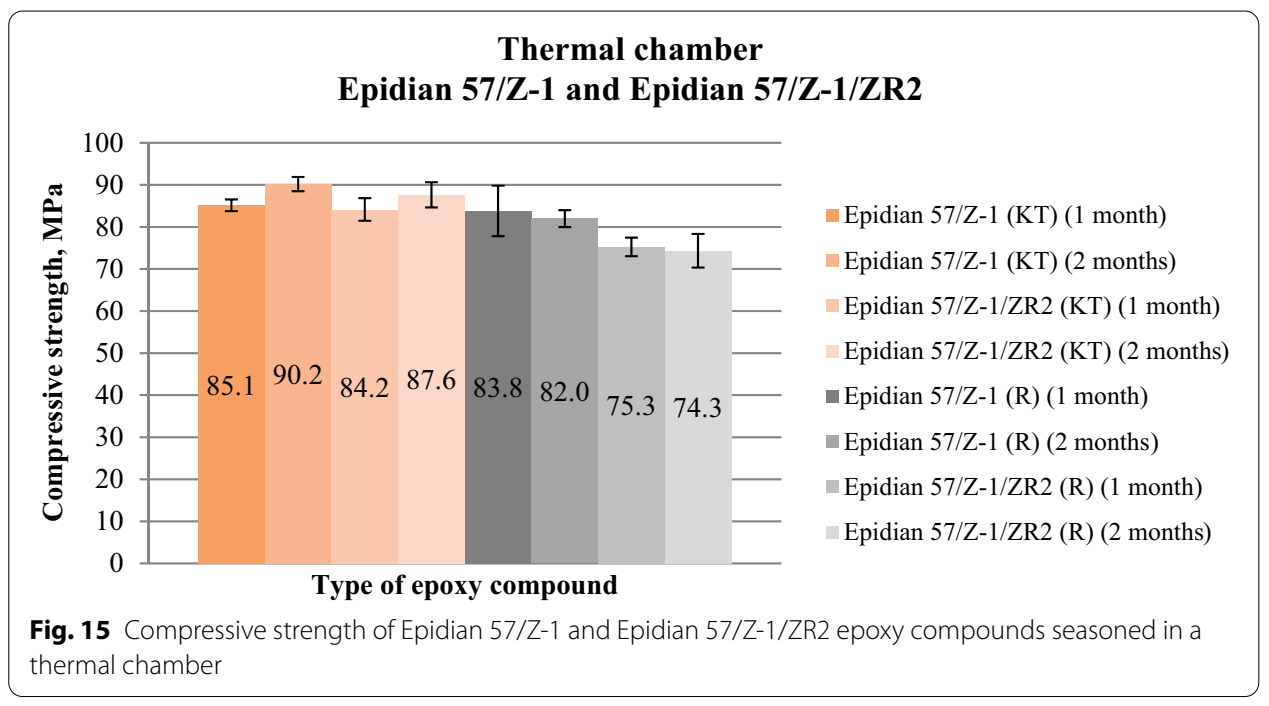




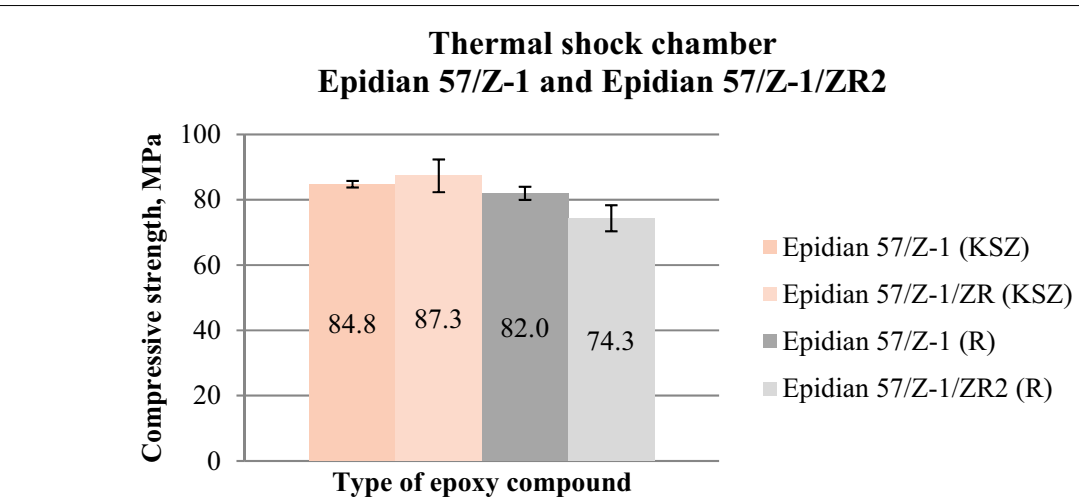

Fig. 16 Compressive strength of Epidian 57/Z-1 and Epidian 57/Z-1/ZR2 epoxy compounds seasoned in a thermal shock chamber
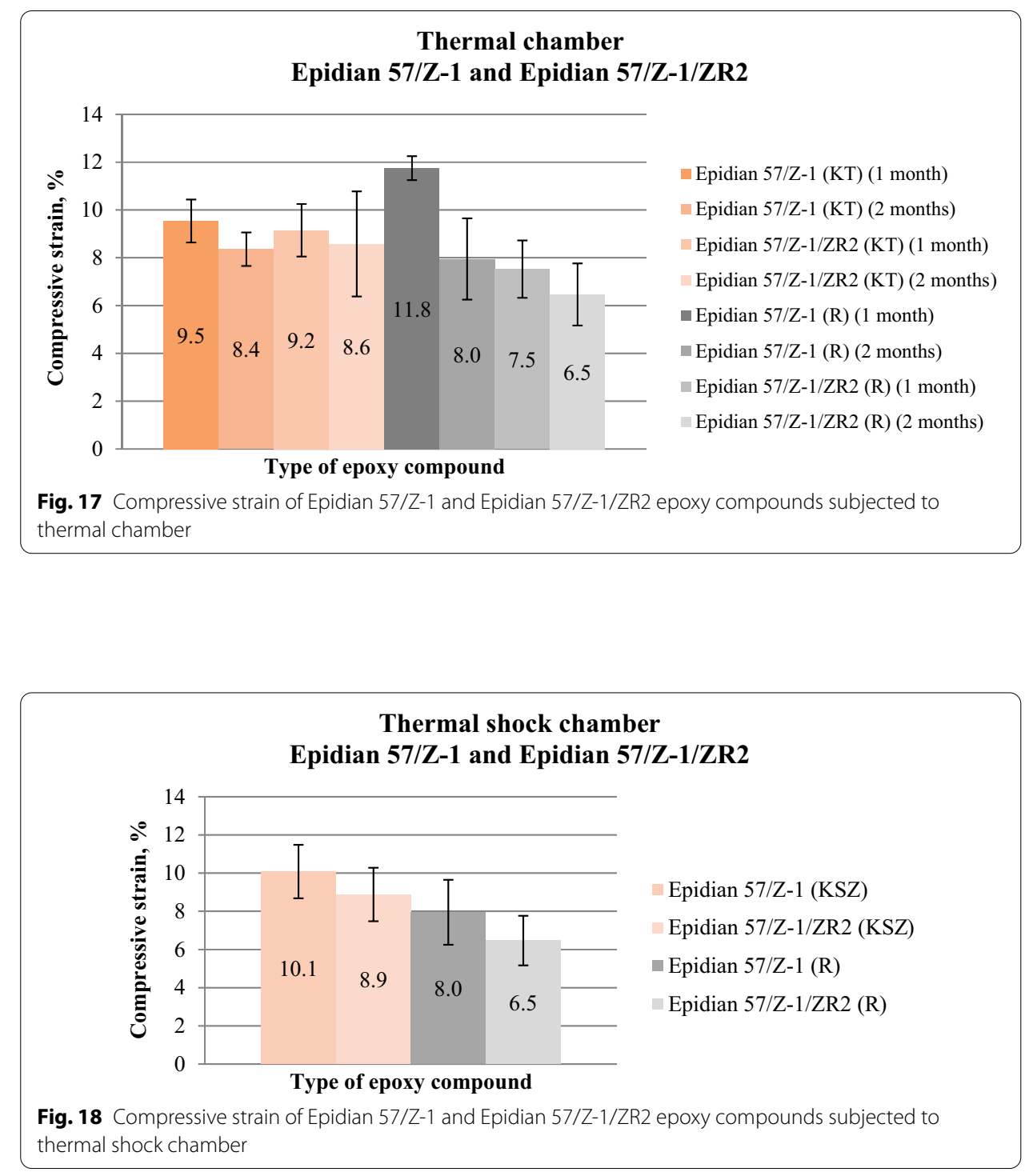
oscillates around $4-6 \%$. The strength of each composition is similar; therefore it can be assumed that the modifying agent has very little effect on reducing the strength of the epoxy compound. The difference between the highest and lowest values is $7 \%$. The influence of elevated temperature on the strength of the epoxy compound is clear, for each of them it increases the strength in comparison with reference epoxy compound.

Based on the comparison of the results for the references samples shown in Fig. 15, a slight decrease in the compressive strength can be observed for the epoxy compounds aged for a longer time compared to the epoxy compounds aged for a shorter time. The decrease for each of the two epoxy compounds is similar at a maximum of $2.2 \%$. The results for the modified and unmodified epoxy compounds in given periods differ from each other, hence it can be concluded that the modification of the epoxy compound with the montmorillonite affects the strength. Epidian 57/Z-1 (R) epoxy compound modified for a longer time has the highest value, while the epoxy compound of Epidian 57/Z-1/ZR2 (R) modified for a shorter time has the lowest value.

The comparison of the results shown in Fig. 16 makes it possible to conclude that the filler content has an insignificant but at the same time beneficial effect on the strength of the tested epoxy compounds, causing its growth. The value of this change is $2.9 \%$. The epoxy compounds after aging are characterized by higher compressive strength at variable temperature.

The analysis of the data presented in Fig. 16 shows that the values of the epoxy compounds seasoned for 2 months are lower than the values of the epoxy compounds seasoned for a month, therefore the extension of the aging time causes the samples seasoned for shorter periods to have a greater shortening. The epoxy compound without the addition of the filler exhibits a clearly greater decrease; its relative reduction is equal to $32.2 \%$. In turn, Epidian 57/Z-1/ZR2 (R) epoxy compound undergoes a much smaller change in the parameter, equal to $13.3 \%$. It can also be read from the drawing that the samples containing the filler are less shortened than the samples without the modifier.

The comparison of the results presented in Fig. 17 shows that extending the time of subjecting the epoxy compounds in the climatic chamber reduces their compressive strain in relation to the monthly aging period. Epidian 57/Z-1 (KT) epoxy compound is characterized by a slightly greater decrease, amounting to $11.6 \%$. It can be concluded that the compressive strain values of the samples of both epoxy compounds in particular aging periods are at a similar level, therefore the influence of the modifier on the value of the discussed parameter is small. The discrepancy between all the results is small; they are all in the range of 8.4-9.5\%. Apart from the unmodified epoxy compound aged for 1 month, a greater reduction is characteristic of the epoxy compounds seasoned at elevated temperature.

The analysis of the data presented in Fig. 17 related to the references samples (R), shows that the values of the epoxy compounds seasoned for 2 months are lower than the values of the epoxy compounds seasoned for a month, therefore the extension of the aging time causes the samples seasoned for shorter periods to have a greater shortening. The epoxy compound without the addition of the filler exhibits a clearly greater decrease; its relative reduction is equal to $32.2 \%$. In turn, Epidian $57 / Z-1 / Z R 2$ (R) epoxy compound undergoes a much smaller change in the parameter, equal to 
13.3\%. It can also be read from the drawing that samples containing the filler are less shortened than the samples without the modifier.

After analysing the data presented in Fig. 18, it was found that the presence of the modifying agent in the epoxy compound subjected to thermal shocks lowers it's the relative contraction value. This change is $11.9 \%$. The influence of the variable aging temperature on the value of the compressive strain was also noticed. It increases the value of this parameter in relation to the reference epoxy compounds.

\section{Discussion}

A detailed comparison of the obtained results is presented in point 3, and in the part concerning the discussion of the results, general observations, prepared on the basis of the detailed results, are presented. Comparing the results of the compressive strength tests of the epoxy compounds containing Epidian 5 and Epidian 57 epoxy resins and two curing agents: polyamide and amine, it was noticed the following trends.

(i) Comparing the type of the epoxy resin and the curing agent that make up the epoxy compounds:

- in each case of operating conditions (Fig. 3 and Figs. 4, 7, and Fig. 8) of the epoxy compounds containing in their composition the base resin unmodified (Epidian 5), the compressive strength is higher for the epoxy compounds containing the amine curing agent. Moreover, this applies to both unmodified and modified compounds;

- in the case of the epoxy compounds containing the modified epoxy resin (Epidian 57), a similar relationship was observed: regardless of the aging conditions and whether the compound is modified with the montmorillonite or not-the epoxy compounds containing the triethylenetetramine curing agent were characterized by higher compressive strength than the polyamide curing agent.

At work [27] was presented that of the compressive strength depending on: (i) the type of the epoxy compound-the type of the curing agent included in the epoxy compounds, containing the same epoxy resin, (ii) the type of the environment, and (iii) the aging time. The results were related to the aging in different water environments and at different times. In this study, a similar dependence was also noticed that the compressive strength depends on the type of the curing included in the epoxy compounds. Okba et al. [17] pointed out that the decrease of the compressive strengths depends on the type of adhesive and also other environmental factors. They tested e.g. exposure to different elevated temperature level and the effect on exposure time. Liu et al. [4] presented among other things the effects of the curing agents and they indicated the influence of the type of curing agent on the mechanical properties of the epoxy composites.

(ii) Considering the effect of the type of the filler on the obtained results, it was observed that:

- in relation to the compositions containing Epidian 5 epoxy resin and PAC curing agent, it was noticed that the filler content slightly affects the strength of the epoxy compounds, in most cases it is lower for the modified epoxy compounds; 
- in the case of Epidian 5/PAC/ZR2 epoxy compound, the addition of a modifying agent to the compound deteriorates its compressive strength measured after operation in a thermal shock chamber for 2 months;

- in the case of Epidian 5/PAC and Epidian 57/PAC unmodified epoxy compounds and modified compounds, the addition of the modifying agent to the compound deteriorates its compressive strength measured after operation in the thermal shock chamber for 2 months;

- comparing the results for Epidian 57/Z-1 and Epidian 57/Z-1/ZR2 epoxy compounds, it was noticed that the filler content had a negligible but beneficial effect on the strength of the tested compounds, causing its growth.

The results of research on epoxy compounds modified with various fillers, including montmorillonite, are presented at $[5,27]$. It has been noticed the addition of montmorillonite has a positive effect on the strength of epoxy compositions.

(iii) While analysing the influence of temperature on the strength results, it was noticed that:

- in the case of Epidian 5/PAC and Epidian 57/PAC unmodified and modified epoxy compounds, the addition of the modifying agent to the compounds deteriorates its compressive strength measured after subjected in a thermal shock chamber for 2 months;

- it can also be seen that the strength of Epidian 5/PAC/ZR2 epoxy compound seasoned in the thermal chamber and the reference compounds is at a very similar level. Thus, for the tested aging temperature, the result of the strength is insignificantly influenced.

The paper [28] presents the impact of the epoxy adhesives aging temperature on the selected mechanical properties. The one of the epoxy compound contained the triethyleneteramine curing agent. It was noticed that the compressive strength of the samples seasoned at ambient temperature increases with the aging time increase. The modified epoxy compounds (by calcium carbonate) with addition of the triethylenetetramine curing agent show a greater compressive strength at ambient temperature than the unmodified this kind of epoxy compound. Rudawska [25] emphasized that both the type of resin and the amount of the curing agent in the epoxy adhesive and also stoichiometric ratio have a significant impact both on the mechanical properties of the epoxy adhesive. Grant et al. [12] noticed that an increase in temperature decreases the adherend yield stress and causes reduction in the failure envelope. The failure load of the lap joints under tension at both +90 and $-40{ }^{\circ} \mathrm{C}$ show the same decrease in the strength of the joint as the bondline thickness increases as those joints tested at $+20^{\circ} \mathrm{C}$.

(iv) considering the influence of the aging time of epoxy compounds in specific temperature conditions, it was noticed that:

- In the case of Epidian 5/PAC and Epidian 5/PAC/ ZR2 reference samples (R), it was noticed that the longer aging time of the samples ( 2 months) had a positive 
effect on the value of the compressive strength, causing it to increase, the samples subjected in the thermal chamber had a similar compressive strength as the reference samples, therefore it can be concluded that the modification of the epoxy compound with the montmorillonite slightly affects the results; similar to Epidian 57/PAC and Epidian 57/PAC/ZR2 epoxy compounds,

- In the case of Epidian 5/Z-1 and Epidian 5/Z-1/ZR2 epoxy compounds, extending the period of placing the epoxy compounds in the thermal chamber from 1 to 2 months increases the strength of both compounds.

The works $[10,27,28]$ also emphasize the significant influence of the temperature and the aging time on the mechanical properties of epoxy compositions, both modified and unmodified. The compressive strength of the epoxy compounds samples seasoned at ambient temperature increases with the aging time increase. The result presented in [24] show that the type of the tested epoxy compound and the quantity and type of a filler determine the effect of the climate chamber ageing and the thermal shock chamber processing on the compressive strength for the tested epoxy compounds. In work [11] demonstrated that both the aging time and the amount of filler have a significant impact on the value of this mechanical characteristic. Hu et al. [19] presented that long-term temperature exposure caused degradation in the joint strength and the failure displacement. In the carried out test it can be noticed that in many cases extending the period of subjecting the epoxy compounds in the thermal chamber from 1 to 2 months increases the strength of the epoxy compound. The degradation of the plastics under the influence of the various factors (temperature, time) primarily causes changes in the molecular structure of the material. However, it should be noted that in some cases, in the first stage of degradation, the degradation factor improves some properties of the material, and above all mechanical strength. This is done by additional cross-linking of the structure material under the influence of, for example, heat. Only at a later stage, for example, excessive cross-linking or reduction of the molecular weight occurs, which contributes to the deterioration of the properties. Therefore, in the presented studies, no deterioration in strength was observed in many cases. However, it is likely that the extension of the service life under the same conditions will contribute to the deterioration of the properties.

The article does not include all stress-strain curves, due to the large amount of data, but the cumulative results are presented in Figs. 5, 6, 9, 10, 13, 14, 17, 18 and the samples of the stress-strain curves presented in Fig. 19. The data presented in Fig. 19 refer to the epoxy compounds: Epidian 5/PAC (R) (1 month)—Fig. 19a, Epidian 5/PAC (KT) (1 month)-Fig. 19b, Epidian 5/PAC (SZ)-Fig. 19c.

Based on the analysis of the stress-strain curves, it was noticed that the stress-strain curve takes the form of a curve for the elastic materials with forced elasticity (referred to as materials with reduced stiffness). This applies to both the analysed reference samples as well as samples subjected to high temperature and thermal shocks.

\section{Conclusion}

The aim of the article was to determine the compressive strength and compressive strain of unmodified and modified epoxy compounds containing the montmorillonite filler, as well as to determine the effect of temperature and aging time on 
(a)

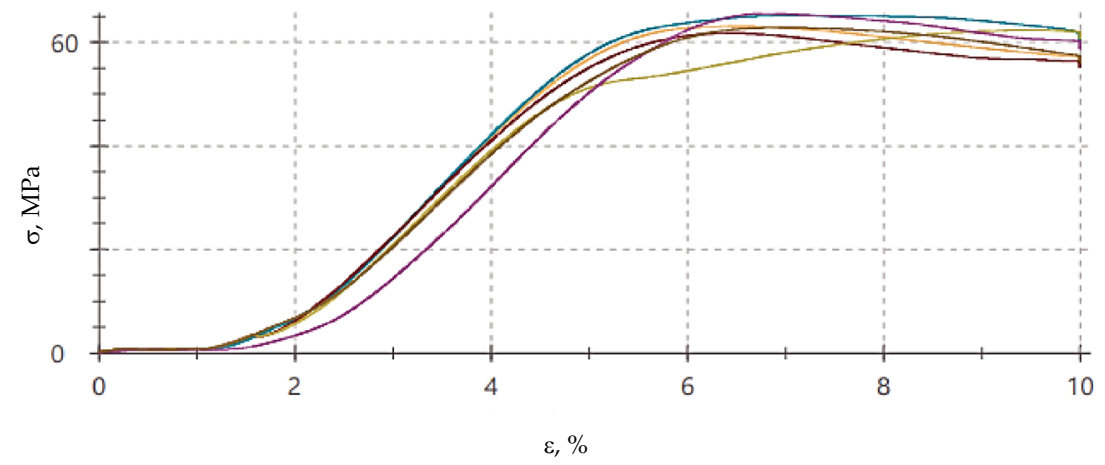

(b)

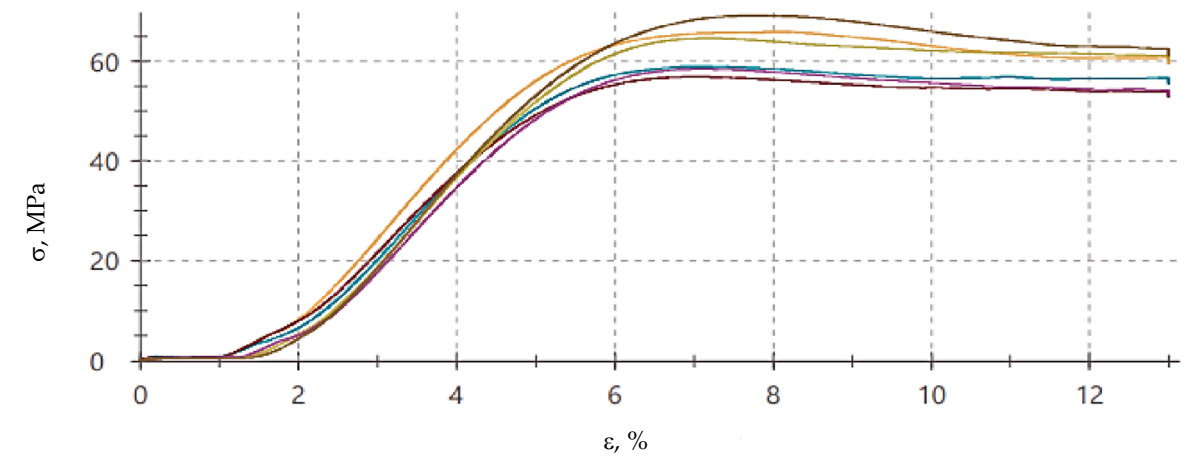

(c)

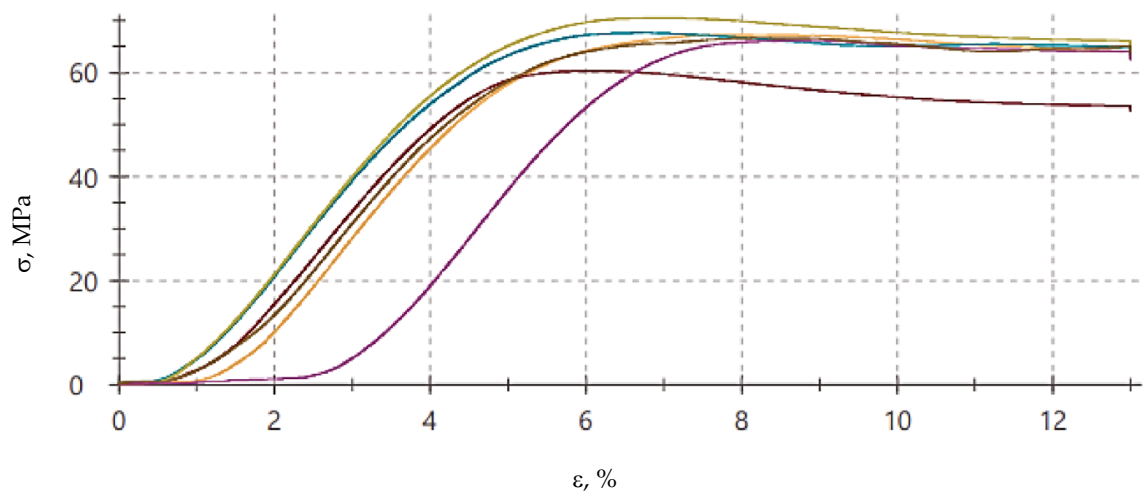

Fig. 19 Stress-strain curves of the epoxy compounds samples: Epidian 5/PAC (R) (1 month), Epidian 5/PAC (KT) (1 month), Epidian 5/PAC (SZ)

the mechanical parameters of the considered epoxy compounds. Based on the obtained results and comparing them with each other, the following conclusions were formulated.

(i) In the most cases, the unmodified epoxy compositions have higher compressive strength.

(ii) The longer aging time was more likely to increase the compressive strength than decrease it. 
(iii) The epoxy compounds subjected at elevated or variable temperatures have higher the compressive strength than the reference epoxy compound.

(iv) Subjecting the samples in the climatic chamber or the thermal shock chamber causes the samples to be more deformed than the reference samples.

To conclude, both the environmental conditions and the modification have the impact on the compressive strength and compressive strain of the epoxy compounds. It is necessary to know what changes occur under the influence of various conditions (e.g. temperature, thermal shock, time, humidity, etc.) in relation to the use of the epoxy compounds, e.g. making the adhesive joints exposed to various external factors. The studies found that in most cases the filler addition in the form of montmorillonite had a beneficial effect on the strength of the tested epoxy compounds that remained in the thermal chamber and the thermal shocks, causing the strength growth. Of course, such a relationship is influenced by other factors, such as the type of epoxy composition or the operating conditions. One of the purposes of using the montmorillonite as filler in polymer composites (including epoxide) is to improve the mechanical properties and increase the thermal stability. The addition of the bentonite fillers may also reduce the flammability of the polymeric materials. The epoxy compounds modified with montmorillonite filler are an interesting subject of the research.

Acknowledgements

Anna Rudawska. Faculty of Mechanical Engineering, Lublin University of Technology, Lublin, Poland.

\section{Authors' contributions}

Anna Rudawska conceived, designed and performed the experiments; analysed the data and wrote the paper. The author read and approved the final manuscript.

\section{Funding}

Lublin University of Technology. Award Number: FD-20/IM-5/093|Recipient: Anna Rudawska, Ph.D., D.Sc. University Prof

\section{Availability of data and materials}

Data sharing not applicable.

\section{Declarations}

Ethics approval and consent to participate

Not applicable.

Consent for publication

Not applicable.

Competing interests

The author declares that she has no competing interests.

Received: 25 July 2021 Accepted: 17 September 2021

Published online: 26 September 2021

\section{References}

1. Adams RD, Comyn J, Wake WC (1997) Structural adhesive joints in engineering book. Springer, United Kingdom

2. Yoon I-N, Lee Y, Kang D, Min J, Won J, Kim M, Kang YS, Kim S, Kim J-J (2011) Modification of hydrogenated Bisphenol A epoxy adhesives using nanomaterials. Int J Adhes Adhes 31:119-125. https://doi.org/10.1016/j.ijadhadh.2010.11. 010

3. Rudawska A, Frigione M (2021) Cold-cured bisphenolic epoxy adhesive filled with low amounts of $\mathrm{CaCO}_{3}$ : effect of the filler on the durability to aqueous environments. Materials 14:1324. https://doi.org/10.3390/ma14061324

4. Liu ZS, Erhan SZ, Calvert PD (2007) Solid freeform fabrication of epoxidized soybean oil/epoxy composite with bis or polyalkyleneamine curing agents. Comp A 38:87-93. https://doi.org/10.1016/j.compositesa.2006.01.009

5. Miturska I, Rudawska A, Müller M, Valášek P (2020) The influence of modification with natural fillers on the mechanical properties of epoxy adhesive compositions after storage time. Materials 13:291. https://doi.org/10.3390/ma130 20291 
6. Cora O, Rohlmann MF, Horst LM, Quinzani MDF (2008) Comparative analysis of nanocomposites based on polypropylene and different montmorillonites. Eur Polym J 44:2749-2760. https://doi.org/10.1016/j.eurpolymj.2008.07.006

7. Alexandre M, Dubois P (2000) Polymer-layered silicate nanocomposites: preparation, properties and uses of a new class of materials. Mat Sci Eng R Reports 28:1-63. https://doi.org/10.1016/S0927-796X(00)00012-7

8. Al-Hussaini AS (2015) Modified nonconventional synthesis of new terpoly(aniline, o-anthranilic acid and o-phenylenediamine)/bentonite composites. Polym Plast Technol Eng 54:61-67. https://doi.org/10.1080/03602559.2014. 935415

9. Viana G, Costa M, Banea MD, da Silva LFM (2016) A review on the temperature and moisture degradation of adhesive joints. Proc Inst Mech Eng Part L J Mat Design Appl 231:488-501

10. Ashcroft IA, Abdel Wahab MM, Crocombe AD, Hughes DJ, Shaw SJ (2001) The effect of environment on fatigue of bonded composite joints. Part 1: testing and fractography. Comp A 32:45-58. https://doi.org/10.1016/S1359$835 \times(00) 00131-7$

11. Rudawska A, Frigione M (2020) Aging effects of aqueous environment on mechanical properties of calcium carbonate-modified epoxy resin. Polymers 12:2541. https://doi.org/10.3390/polym12112541

12. Grant LDR, Adams RD, da Silva LFM (2009) Effect of the temperature on the strength of adhesively bonded single lap and $\mathrm{T}$ joints for the automotive industry. Int J Adhes Adhes 29:535-524

13 Rudawska A, Wahab MA, Müller M (2020) Effect of ageing process on mechanical properties of adhesive tubular butt joints in aqueous environment. Int J Adhes Adhes 96:102466. https://doi.org/10.1016/j.ijadhadh.2019.102466

14. Blackburn BP, Tatar J, Douglas EP, Hamilton HR (2015) Effects of hygrothermal conditioning on epoxy adhesives used in FRP composites. Constr Build Mater 96:679-689. https://doi.org/10.1016/j.conbuildmat.2015.08.056

15. Zhang F, Yang X, Xia Y, Zhou Q, Wang H-P, Yu T-X (2015) Experimental study of strain rate effects on the strength of adhesively bonded joints after hygrothermal exposure. Int J Adhes Adhes 56:3-12. https://doi.org/10.1016/j.ijadh adh.2014.07.008

16. Han X, Crocombe AD, Anwar SNR, Hua P (2014) The strength prediction of adhesive single lap joints exposed to long term loading in a hostile environment. Int J Adhes Adhes 55:1-11. https://doi.org/10.1016/j.jiadhadh.2014.06 013

17. Okba SH, Nasr E-SA, Helmy All, Yousef IA-I (2017) Effect of thermal exposure on the mechanical properties of polymer adhesives. Con Build Mat 135:490-504. https://doi.org/10.1016/j.conbuildmat.2016.12.067

18. da Silva LFM, Adams RD (2017) Joint strength predictions for adhesive joints to be used over a wide temperature range. Int J Adhes Adhes 27:362-379. https://doi.org/10.1016/j.ijadhadh.2006.09.007

19. Hu P, Han X, Li WD, Li L, Shao Q (2013) Research on the static strength performance of adhesive single lap joints subjected to extreme temperature environment for automotive industry. Int J Adhes Adhes 41:119-126. https://doi. org/10.1016/j.ijadhadh.2012.10.010

20 Beber VC, Schneider B, Brede M (2016) Influence of temperature on the fatigue behaviour of a toughened epoxy adhesive. J Adhes 92:778-794. https://doi.org/10.1080/00218464.2015.1114927

21. Lee J, Soutis C (2007) A study on the compressive strength of thick carbon fibre-epoxy laminates. Comp Sci Technol 67:2015-2026. https://doi.org/10.1016/j.compscitech.2006.12.001

22 Soutis C (1991) Measurement of the static compressive strength of carbon-fibre/epoxy laminates. Comp Sci Technol 42:373-392. https://doi.org/10.1016/0266-3538(91)90064-V

23. Jin NJ, Seung IS, Choi YS, Yeon J (2017) Prediction of early-age compressive strength of epoxy resin concrete using the maturity method. Constr Build Mat 152:990-998. https://doi.org/10.1016/j.conbuildmat.2017.07.066

24. Rudawska A (2020) Experimental study of mechanical properties of epoxy compounds modified with calcium carbonate and carbon after hygrothermal exposure. Materials 13:5439. https://doi.org/10.3390/ma13235439

25. Rudawska A (2021) Mechanical properties of selected epoxy adhesive and adhesive joints of steel sheets. Appl Mech 2:108-126. https://doi.org/10.3390/applmech2010007

26. Rudawska A (2021) Mechanical properties of epoxy compounds based on bisphenol a aged in aqueous environments. Polymers 13(6):952. https://doi.org/10.3390/polym13060952

27. Miturska I, Rudawska A, Müller M, Hromasová M (2021) The influence of mixing methods of epoxy composition ingredients on selected mechanical properties of modified epoxy construction materials. Materials 14(2):411. https://doi.org/10.3390/ma14020411

28. Rudawska A (2019) The impact of seasoning conditions on mechanical properties of modified and unmodified epoxy adhesive compounds. Polymers 11:804. https://doi.org/10.3390/polym11050804

\section{Publisher's Note}

Springer Nature remains neutral with regard to jurisdictional claims in published maps and institutional affiliations. 